\title{
TP53 mutational analysis supports monoclonal origin of biphasic sarcomatoid urothelial carcinoma (carcinosarcoma) of the urinary bladder
}

Andrew B Armstrong ${ }^{1}$, Mingsheng Wang ${ }^{1}$, John N Eble ${ }^{1}$, Gregory T MacLennan², Rodolfo Montironi ${ }^{3}$, Puay-Hoon Tan $^{4}$, Antonio Lopez-Beltran ${ }^{5}$, Shaobo Zhang ${ }^{1}$, Lee Ann Baldridge ${ }^{1}$, Helena Spartz ${ }^{1}$ and Liang Cheng ${ }^{1,6}$

${ }^{1}$ Department of Pathology, Indiana University School of Medicine, Indianapolis, IN, USA; ${ }^{2}$ Department of Pathology, Case Western Reserve University, Cleveland, OH, USA; ${ }^{3}$ Institute of Pathological Anatomy and Histopathology, School of Medicine, Polytechnic University of the Marche Region (Ancona), United

Hospitals, Ancona, Italy; ${ }^{4}$ Department of Pathology, Singapore General Hospital, Singapore, Singapore; ${ }^{5}$ Department of Pathology, Cordoba University, Cordoba, Spain and ${ }^{6}$ Department of Laboratory Medicine, Indiana University School of Medicine, Indianapolis, IN, USA

\begin{abstract}
Sarcomatoid urothelial carcinoma of the urinary bladder is an uncommon neoplasm with biphasic morphology exhibiting both epithelial and sarcomatoid components. Whether this tumor arises from a single cancer stem cell with subsequent differentiation or represents collision of the progeny of two separate cancer stem cells is a matter of controversy. To clarify its clonal origin, we analyzed the TP53 mutation status of a series of 17 sarcomatoid urothelial carcinomas using single-strand conformation polymorphism, DNA sequencing and p53 immunohistochemistry. Sarcomatoid and epithelial tumor components were separately microdissected using laser capture microdissection. Five out of the 17 sarcomatoid urothelial carcinomas contained TP53 point mutations in exons 5 and 8 . In all five cases, the TP53 point mutations were identical in both the epithelial and sarcomatoid components. The sarcomatoid and epithelial tumor components in all 17 cases showed concordant p53 expression patterns. Our results suggest that despite their conspicuous divergence at the phenotypic level, the sarcomatoid and carcinomatoid elements of this uncommon tumor share a common clonal origin. Modern Pathology (2009) 22, 113-118; doi:10.1038/modpathol.2008.176; published online 7 November 2008
\end{abstract}

Keywords: urinary bladder; sarcomatoid urothelial carcinoma; tumorigenesis; molecular genetics; cancer stem cells; clonality

Sarcomatoid urothelial carcinoma of the urinary bladder is an uncommon neoplasm with both epithelial and sarcomatoid components. Although some investigators favor the use of the term carcinosarcoma, the current recommendation by the World Health Organization is to use the term sarcomatoid carcinoma for this entity. ${ }^{1}$ Patients with this neoplasm are predominantly male. Although most patients present between 60 and 70 years of age, patients as young as 2 years old have been

Correspondence: Dr L Cheng, MD, Department of Pathology and Laboratory Medicine, Indiana University School of Medicine, 350 West 11th Street, Clarian Pathology Laboratory Room 4010, Indianapolis, IN 46202, USA. E-mail: liang_cheng@yahoo.com

Dr AB Armstrong received the Excellence in Urologic Research Award for Pathologists-in-training from the International Society of Urologic Pathology for this work.

Received 21 March 2008; revised 23 September 2008; accepted 3 October 2008; published online 7 November 2008 reported. ${ }^{2,3}$ Sarcomatoid carcinoma typically presents at an advanced stage and is associated with a poor prognosis. Etiologic factors are largely unknown, although some believe previous radiotherapy may be a significant contributing factor. ${ }^{4,5}$

The epithelial components most frequently described in sarcomatoid carcinoma include urothelial carcinoma, small-cell carcinoma, squamous carcinoma and adenocarcinoma. Chondrosarcoma, leiomyosarcoma, malignant fibrous histiocytoma, osteosarcoma, rhabdomyosarcoma and undifferentiated sarcoma comprise the most frequently identified mesenchymal components. The origin of this unusual lesion is controversial. Some investigators believe that it represents the collision of two separate malignant tumors occurring independently and synchronously in the same location. ${ }^{6-11}$ Others suggest that sarcomatoid carcinoma has a monoclonal origin with subsequent differentiation into its 
carcinomatoid and sarcomatoid elements. ${ }^{12,13}$ In this study we analyzed the TP53 mutation status of a series of 17 sarcomatoid urothelial carcinomas using single-strand conformation polymorphism (SSCP), DNA sequencing and immunohistochemistry to clarify the clonal origin of these different tumor components.

\section{Materials and methods}

\section{Patients}

Seventeen patients (sixteen men and one woman) diagnosed with sarcomatoid carcinoma of the urinary bladder between 1992 and 2006 were included in this study. The age range at tumor resection was 44-83 years, with a mean age of 64 years. Tumors were diagnosed by light microscopy with the criteria established for sarcomatoid carcinoma of the urinary bladder according to the World Health Organization classification system. ${ }^{1}$ The tumor, lymph node and metastasis classification system (2002) was used for pathological staging. ${ }^{14}$ Among the seventeen cases, seven were diagnosed as stage pT2 and six as pT3. Four patients were managed surgically by transurethral resection, precluding definitive pathologic staging.

\section{Tumor Samples and Microdissection}

Archival paraffin blocks from 17 cases of sarcomatoid carcinoma of the urinary bladder were collected from the participating institutions. Serial $5-\mu \mathrm{m}$-thick paraffin sections were prepared from each block. Tumor cells from epithelial and sarcomatoid components were separately dissected after routine H\&E staining with a PixCell II Laser Capture Microdissection System (Arcturus Engineering, Mountain View, CA, USA) as previously described. ${ }^{15-17}$ Approximately 600 cells from each phenotypically different tumor component were microdissected as demonstrated in Figure 1. Adjacent normal urothelium was microdissected for use as a control. The microdissected tissue was incubated in $50 \mu \mathrm{l}$ of digestion buffer containing $10 \mathrm{mM}$ Tris-HCl, $1 \mathrm{mM}$ EDTA, 1\% Tween 20 and $5 \mathrm{mg} / \mathrm{ml}$ of proteinase $\mathrm{K}(\mathrm{pH} 8.3)$ at $37^{\circ} \mathrm{C}$ overnight. The samples were boiled for $10 \mathrm{~min}$ to inactivate proteinase $\mathrm{K}$ and subjected to a phenol-chloroform extraction (phenol:chloroform:isoamyl alcohol $=25: 24: 1$ ). The genomic DNA was dissolved in $30 \mu \mathrm{l}$ of $\mathrm{ddH}_{2} \mathrm{O}$ after phenol-chloroform extraction.

\section{SSCP Analysis}

TP53 mutation screening in exons 5,7 and 8 was performed using SSCP. TP53 sequences in exons 5, 7 and 8 were amplified by hot-start PCR using the primers listed in Table $1 .{ }^{18,19}$ TP53 sequences were amplified using $3 \mu \mathrm{l}$ of genomic DNA, $2.3 \mathrm{mM}$
$\mathrm{MgCl}_{2}, 10 \mathrm{mM}$ Tris-HCl (pH 8.3), $50 \mathrm{mM} \mathrm{KCl,}$ $0.2 \mu \mathrm{M}$ deoxynucleotide triphosphates, $0.8 \mu \mathrm{Ci}$ $\alpha{ }^{32} \mathrm{PdATP}, 0.33 \mu \mathrm{M}$ of each primer and 1 unit of Taq DNA polymerase (Bio-Rad, Hercules, CA, USA) with a final volume of $25 \mu \mathrm{l}$. Each PCR protocol had an initial denaturing step of $95^{\circ} \mathrm{C}$ for $5 \mathrm{~min}$, followed by 35 cycles at $95^{\circ} \mathrm{C}$ for $30 \mathrm{~s}, 55^{\circ} \mathrm{C}$ for $30 \mathrm{~s}$ and $72^{\circ} \mathrm{C}$ for $30 \mathrm{~s}$, which was then followed by a single final extension step at $72^{\circ} \mathrm{C}$ for $7 \mathrm{~min}$. PCR products were diluted with loading buffer $(0.04 \%$ blomophenol blue, $0.04 \%$ xylene cyanol $\mathrm{FF}, 5 \%$ glycerol) and separated by a nondenaturing $6 \%$ polyacrylamide gel at $150 \mathrm{~V}$ overnight. After electrophoresis, the gels were fixed in $10 \%$ acetate acid containing $20 \%$ methanol, dried on blotting paper on a vacuum gel dryer and exposed to X-ray film for 2-18 h. Developed films were evaluated by visual inspection.

\section{TP53 Mutation Analysis}

TP53 sequences in exons 5,7 and 8 were amplified by PCR using the primers listed in Table 1 according to described protocols. The PCR products were purified with the QIAquick PCR Purification Kit (QIAGEN Sciences, MD, USA) and the DNA concentration adjusted to $20 \mathrm{ng} / \mu \mathrm{l}$. Purified PCR product was sequenced with the ABI Prism 3100 Genetic Analyzer (Applied Biosystems, Foster City, CA, USA) using the designated primer.

\section{p53 Immunohistochemistry}

Immunostaining for p53 was performed on paraffinembedded tissue sections using the peroxidaselabeled streptavidin-biotin method. 5 - $\mu$ m-thick tissue sections from each case were deparaffinized in xylene for $5 \mathrm{~min}$ and then rehydrated through graded ethanol to distilled water. Antigen retrieval was achieved by heating the slides with DAKO antigen retrieval solution, $\mathrm{pH}$ 6.0 (Dako Corporation, Carpintera, CA, USA) at $95^{\circ} \mathrm{C}$ for $10 \mathrm{~min}$. Endogenous peroxidase was blocked by incubating the slides in $3 \% \mathrm{H}_{2} \mathrm{O}_{2}$ for $5 \mathrm{~min}$. Detection of p53 protein was performed using a monoclonal antibody against p53 (Dako Corporation). The primary antibody was incubated for $10 \mathrm{~min}$, followed by biotinylated secondary antibody and peroxidase-labeled streptavidin. 3,3-Diaminobenzidine was used as the chromogen. The staining was evaluated by light microscopy using a three-tiered system $(1+, 2+$ and $3+)$, corresponding with the intensity of the nuclear staining. The percentage of tumor cells staining was also recorded. ${ }^{20,21}$

\section{Results}

Point mutations were identified in 5 of 17 cases by SSCP as well as TP53 gene sequencing of exons 5, 7 and 8 . A total of $100 \%$ concordance was observed 

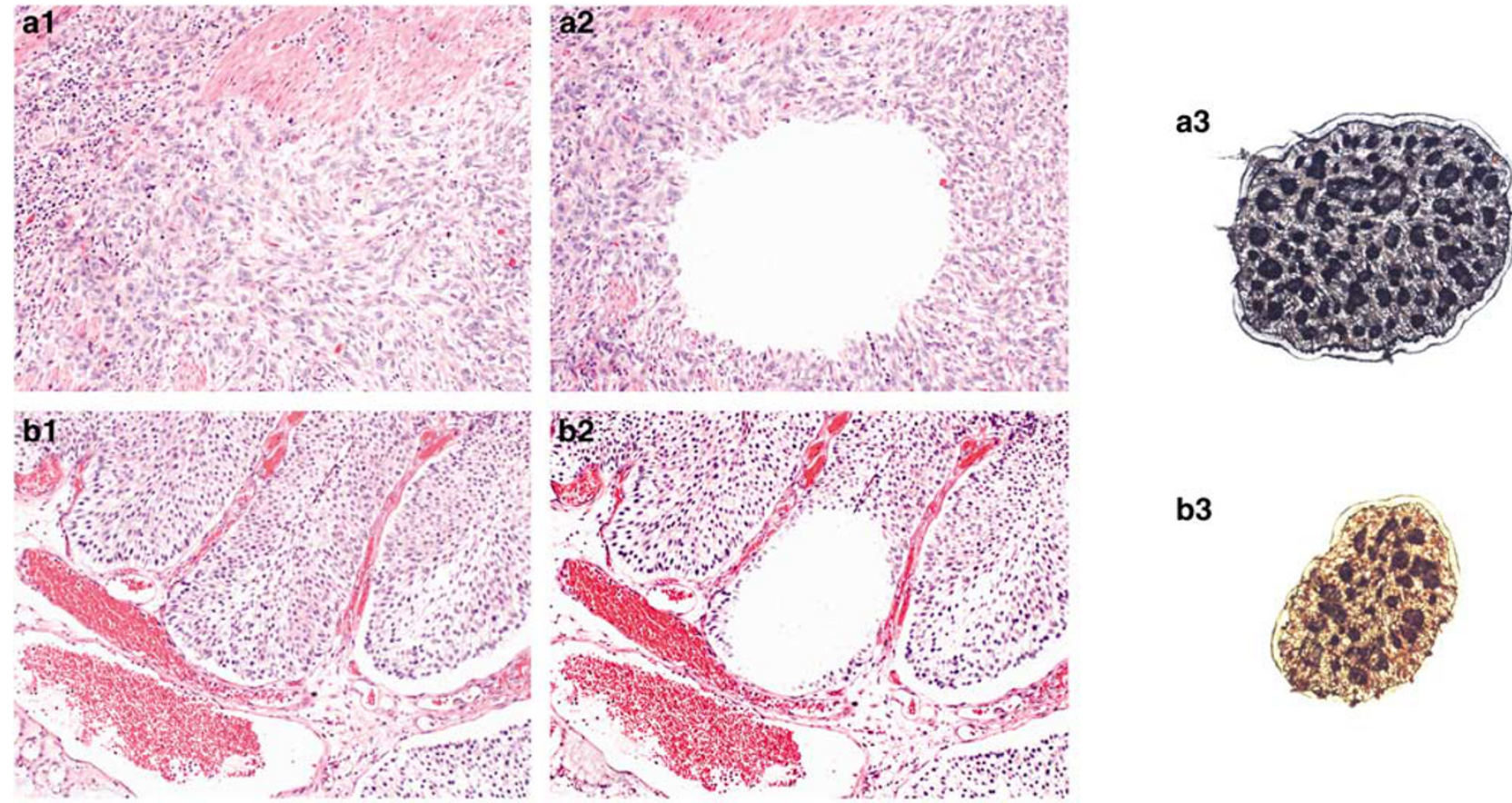

\section{Case 15}

\section{c Normal}

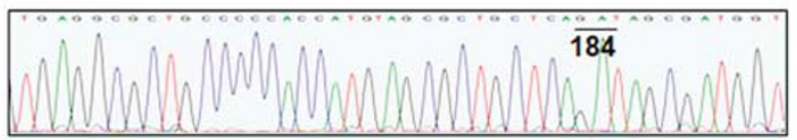

TCC component

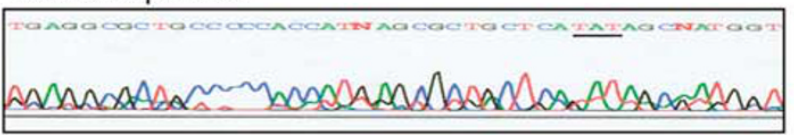

b3

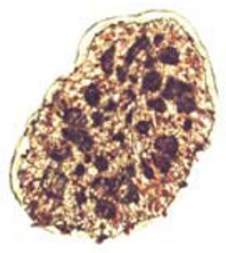

Sarcomatoid component

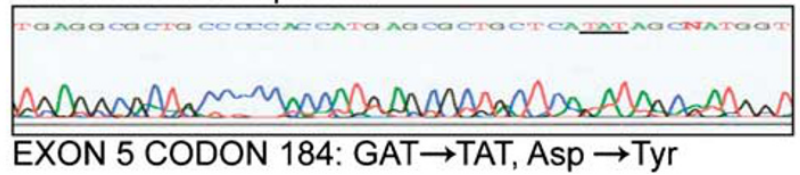

Figure 1 Laser capture microdissection of sarcomatoid urothelial carcinoma of the urinary bladder (a1-b3): hematoxylin and eosinstained sections showing sarcomatoid (a1) and epithelial (transitional cell carcinoma, TCC) (b1) components before microdissection; corresponding sarcomatoid component (a2) and epithelial component (b2) after microdissection; and laser-captured sarcomatoid (a3) and epithelial (b3) tumor cells. (c) Case 15: point mutation at exon 5 codon 184: (GAT $\rightarrow$ TAT, Asp $\rightarrow$ Tyr) revealing identical mutations in epithelial components (middle panel) and sarcomatoid components (bottom panel); normal tissue did not harbor the mutation in the corresponding codon (top panel).

between the tumors with mutations detected by SSCP and those with point mutations identified by DNA sequencing. The mutation patterns were identical in the separately microdissected epithelial and sarcomatoid components in all five cases (Table 2). Normal tissue did not show TP53 mutations in any of the 17 cases studied.

Four tumors exhibited point mutations in exon 8 (codons 261, 268, 272 and 275). Three of these mutations resulted in amino-acid substitutions (codon 268: serine to arginine, codon 272: alanine to proline and codon 275: alanine to valine). The $\mathrm{T}$ to $\mathrm{C}$ mutation at codon 261 was a silent mutation.
Two tumors had point mutations in exon 5 (both at codon 184) with identical $G$ to $T$ substitutions resulting in an aspartic acid to tyrosine alteration. One of these two tumors had a second mutation in codon 268 in exon 8.

Immunohistochemistry detected moderate to strong p53 expression in eight cases, two of which harbored TP53 mutations (Table 2; Figure 2). The sarcomatoid and epithelial tumor components showed concordant p53 expression patterns and intensities. The three cases with identified point mutations that did not show increased p53 staining were negative in both the epithelial and sarcomatoid 
Table 1 Primers used for p53 mutation detection

\begin{tabular}{llc}
\hline $\begin{array}{l}\text { Exon } \\
\text { no. }\end{array}$ & Primer sequence & $\begin{array}{c}\text { PCR } \\
\text { product }(\mathrm{bp})\end{array}$ \\
\hline 5 & 5-IA CCTGACTTTCAACTCTGTCTC & 158 \\
& 5-IB ACTGCTTGTAGATGGCCA TG & 176 \\
& 5-IIA CAGCTGTGGGTTGATTCCAC & 141 \\
7 & 5-IIB CTGGGGACCCTGGGCAAC & 135 \\
& 7-IA AGGCGCACTGGCCTCATCTT & 130 \\
& 7-IB TCCAGTGTGATGATGGTGAGG & 127 \\
& 7-IIA CATGTGTAACATTTCCTGCAT & \\
& 7-IIB GAGGCAAGCAGAGGCTGG & \\
& 8-IA CCTTACTGCCTCTTGCTTCTC & 130 \\
& 8-IB CTTGCGGAGATTCTCTTCCTC & \\
& 8-IIA TTGTGCCTGTCCTGGGAGAG & \\
\hline
\end{tabular}

areas. Of the 12 cases without identified TP53 mutations, half (six) demonstrated nuclear p53 staining and half had no increased staining. The p53 expression patterns were identical in both the carcinomatoid and sarcomatoid areas.

\section{Discussion}

In this study we analyzed TP53 mutation status and p53 protein expression in both the sarcomatoid and epithelial components of cases of sarcomatoid urothelial carcinoma. Concordant TP53 mutations and p53 protein expression support the monoclonal origin of both components.

Table 2 Detection of TP53 mutations in sarcomatoid urothelial carcinoma

\begin{tabular}{|c|c|c|c|c|c|c|}
\hline $\begin{array}{l}\text { Case } \\
\text { no. }\end{array}$ & Component & $S S C P$ & Exon 5 & Exon 7 & Exon 8 & p53 IHC \\
\hline \multirow[t]{2}{*}{1} & $\mathrm{C}$ & Mutation detected & No mutation & No mutation & $\begin{array}{l}\text { Codon } 272 \text {, } \\
\text { GCT } \rightarrow \text { CCT, Ala } \rightarrow \text { Pro }\end{array}$ & $3+, 90 \%$ \\
\hline & $\mathrm{S}$ & Mutation detected & No mutation & No mutation & $\begin{array}{l}\text { Codon } 272 \text {, } \\
\text { GCT } \rightarrow \text { CCT, Ala } \rightarrow \text { Pro }\end{array}$ & $3+, 90 \%$ \\
\hline \multirow[t]{2}{*}{2} & $\mathrm{C}$ & No mutation & No mutation & No mutation & No mutation & $3+, 50 \%$ \\
\hline & $\mathrm{S}$ & No mutation & No mutation & No mutation & No mutation & $3+, 50 \%$ \\
\hline \multirow[t]{2}{*}{3} & $\mathrm{C}$ & No mutation & No mutation & No mutation & No mutation & $3+, 90 \%$ \\
\hline & $\mathrm{S}$ & No mutation & No mutation & No mutation & No mutation & $3+, 90 \%$ \\
\hline \multirow[t]{2}{*}{4} & $\mathrm{C}$ & No mutation & No mutation & No mutation & No mutation & NEG \\
\hline & $\mathrm{S}$ & No mutation & No mutation & No mutation & No mutation & NEG \\
\hline \multirow[t]{2}{*}{5} & $\mathrm{C}$ & No mutation & No mutation & No mutation & No mutation & NEG \\
\hline & $\mathrm{S}$ & No mutation & No mutation & No mutation & No mutation & NEG \\
\hline \multirow[t]{2}{*}{6} & $\mathrm{C}$ & No mutation & No mutation & No mutation & No mutation & NEG \\
\hline & $\mathrm{S}$ & No mutation & No mutation & No mutation & No mutation & NEG \\
\hline \multirow[t]{2}{*}{7} & $\mathrm{C}$ & No mutation & No mutation & No mutation & No mutation & $3+, 90 \%$ \\
\hline & $\mathrm{S}$ & No mutation & No mutation & No mutation & No mutation & $3+, 90 \%$ \\
\hline \multirow[t]{2}{*}{8} & $\mathrm{C}$ & No mutation & No mutation & No mutation & No mutation & $3+, 40 \%$ \\
\hline & $\mathrm{S}$ & No mutation & No mutation & No mutation & No mutation & $3+, 20 \%$ \\
\hline \multirow[t]{2}{*}{9} & $\mathrm{C}$ & No mutation & No mutation & No mutation & No mutation & $2+, 15 \%$ \\
\hline & $\mathrm{S}$ & No mutation & No mutation & No mutation & No mutation & $2+, 15 \%$ \\
\hline \multirow[t]{2}{*}{10} & $\mathrm{C}$ & No mutation & No mutation & No mutation & No mutation & $3+, 90 \%$ \\
\hline & $\mathrm{S}$ & No mutation & No mutation & No mutation & No mutation & $3+, 90 \%$ \\
\hline \multirow[t]{2}{*}{11} & $\mathrm{C}$ & Mutation detected & No mutation & No mutation & $\begin{array}{l}\text { Codon 261, } \\
\text { GGT } \rightarrow \text { GGC, Gly } \rightarrow \text { Gly }\end{array}$ & $2+, 15 \%$ \\
\hline & $\mathrm{S}$ & Mutation detected & No mutation & No mutation & $\begin{array}{l}\text { Codon 261, } \\
\text { GGT } \rightarrow \text { GGC, Gly } \rightarrow \text { Gly }\end{array}$ & $2+, 15 \%$ \\
\hline \multirow[t]{2}{*}{12} & $\mathrm{C}$ & No mutation & No mutation & No mutation & No mutation & NEG \\
\hline & $\mathrm{S}$ & No mutation & No mutation & No mutation & No mutation & NEG \\
\hline \multirow[t]{2}{*}{13} & $\mathrm{C}$ & No mutation & No mutation & No mutation & No mutation & NEG \\
\hline & $\mathrm{S}$ & No mutation & No mutation & No mutation & No mutation & NEG \\
\hline \multirow[t]{2}{*}{14} & $\mathrm{C}$ & Mutation detected & No mutation & No mutation & $\begin{array}{l}\mathrm{CODON} 275, \\
\mathrm{GCC} \rightarrow \mathrm{GTC}, \mathrm{Ala} \rightarrow \mathrm{Val}\end{array}$ & NEG \\
\hline & $\mathrm{S}$ & Mutation detected & No mutation & No mutation & $\begin{array}{l}\text { Codon } 275 \text {, } \\
\text { GCC } \rightarrow \text { GTC, Ala } \rightarrow \text { Val }\end{array}$ & NEG \\
\hline \multirow[t]{2}{*}{15} & $\mathrm{C}$ & Mutation detected & $\begin{array}{l}\text { CODON 184, } \\
\text { GAT } \rightarrow \text { TAT, Asp } \rightarrow \text { Tyr }\end{array}$ & No mutation & No mutation & NEG \\
\hline & $\mathrm{S}$ & Mutation detected & $\begin{array}{l}\text { CODON 184, } \\
\text { GAT } \rightarrow \text { TAT, Asp } \rightarrow \text { Tyr }\end{array}$ & No mutation & No mutation & NEG \\
\hline \multirow[t]{2}{*}{16} & $\mathrm{C}$ & No mutation & No mutation & No mutation & No mutation & NEG \\
\hline & $\mathrm{S}$ & No mutation & No mutation & No mutation & No mutation & NEG \\
\hline \multirow[t]{2}{*}{17} & $\mathrm{C}$ & Mutation detected & $\begin{array}{l}\text { CODON 184, } \\
\text { GAT } \rightarrow \text { TAT, Asp } \rightarrow \text { Tyr }\end{array}$ & No mutation & $\begin{array}{l}\text { Codon 268, } \\
\text { AGC } \rightarrow \text { CGC, Ser } \rightarrow \text { Arg }\end{array}$ & NEG \\
\hline & $\mathrm{S}$ & Mutation detected & $\begin{array}{l}\text { CODON 184, } \\
\text { GAT } \rightarrow \text { TAT, Asp } \rightarrow \text { Tyr }\end{array}$ & No mutation & $\begin{array}{l}\text { Codon 268, } \\
\text { AGC } \rightarrow \text { CGC, Ser } \rightarrow \text { Arg }\end{array}$ & NEG \\
\hline
\end{tabular}

C, transitional cell (urothelial) carcinoma component; S, sarcomatoid carcinoma component; IHC, immunohistochemistry; SSCP, single-strand conformation polymorphism; NEG, negative. 


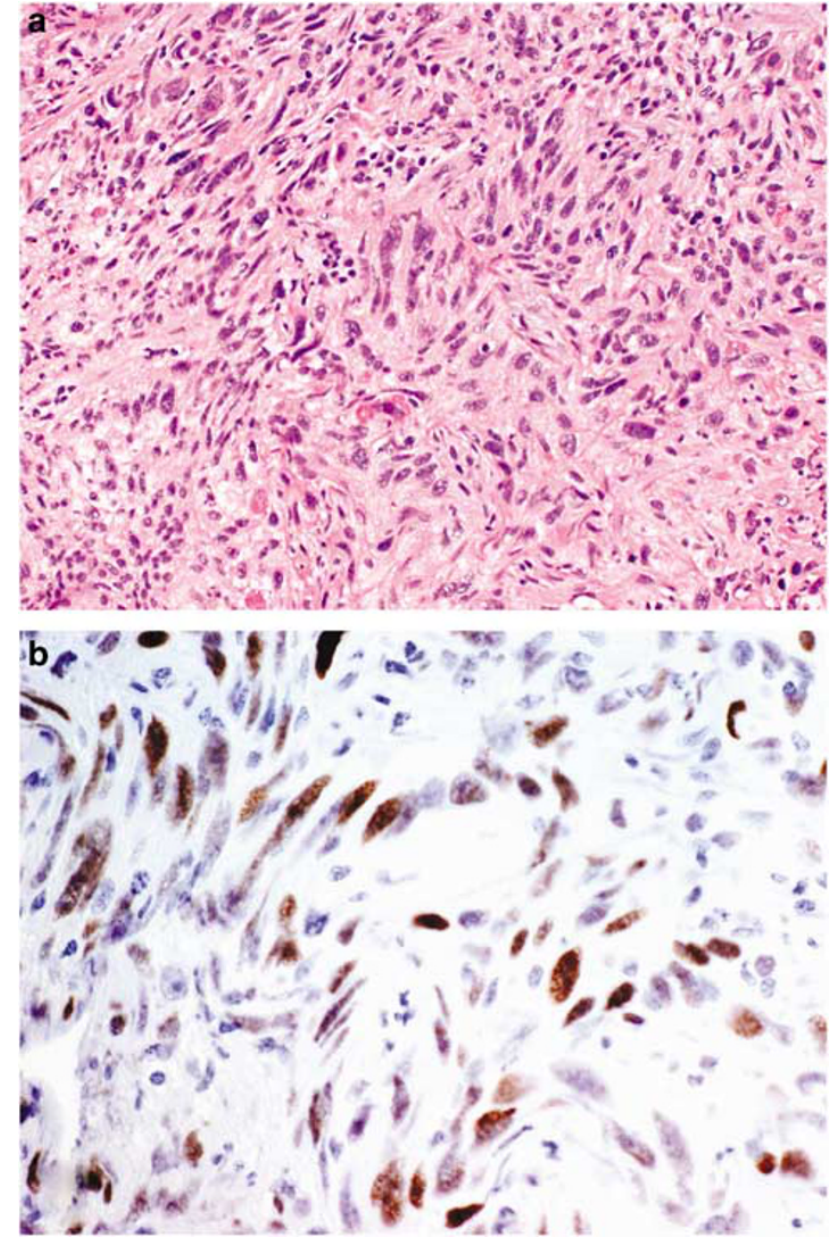

Figure 2 p53 immunohistochemistry in sarcomatoid urothelial carcinoma. Sarcomatoid components showed strong p53 positivity (b); the same components in hematoxylin and eosin-stained sections (a).

The histogenesis of the epithelial and sarcomatoid elements of sarcomatoid carcinoma of the urinary bladder has been a matter of controversy involving two main theories. According to the collision theory, the two components are similar only in their location and synchrony, developing independently from two separate stem cells of epithelial and mesenchymal origin. The divergence hypothesis contends that the lesion develops from a monoclonal origin (a single cancer stem cell) and subsequently diverges into morphologically dissimilar components. Histologic support for the divergence theory focused on identification of a 'transition zone' between the histologically dissimilar areas to indicate divergence from a monoclonal origin. $^{22}$ More recently, concordant X-chromosome inactivation and significant overlap in loss of heterozygosity were reported in separately microdissected components of sarcomatoid carcinoma of the urinary bladder in a study by Sung et $a l^{23}$ supporting a monoclonal origin for both components. Gronau et $a l^{24}$ obtained similar results, finding that the tumor components showed overlapping chromosomal altera- tions as well as additional nonoverlapping alterations. These secondary mutational aberrations were thought to represent events significant in the divergence occurring after the initial tumorigenesis. ${ }^{24}$

Although TP53 mutations are common in urothelial carcinomas, particularly in high-grade and highstage cancers, TP53 mutation analysis has not previously been utilized to evaluate the molecular characteristics of the morphologically distinct components of sarcomatoid carcinoma of the urinary bladder. TP53 exons 5-8, corresponding to the DNAbinding domain, are considered to be the region most frequently harboring point mutations in bladder carcinomas. ${ }^{25-27}$ Among these exons, 5 and 8 contain the majority of mutations. ${ }^{28}$ We focused our screening on exons 5, 7 and 8 allowing us to screen those exons most likely to harbor mutations without significantly decreasing our sensitivity. However, the possibility of additional mutations in less common regions cannot be ruled out.

SSCP and DNA sequencing identified TP53 mutations in exons 5,7 or 8 in 5 of the 17 cases we evaluated. The concordance between SSCP and DNA sequencing was $100 \%$ in the current investigation. In addition, we found that the mutations identified in the microdissected epithelial and sarcomatoid components were identical in all five cases. The sarcomatoid and epithelial tumor components in all cases showed concordant p53 expression patterns. Our data suggest a common clonal origin of the phenotypically different tumor components. The TP53 mutations probably occurred early in the common tumorigenesis of these morphologically distinct tumor components. Subsequently, these lesions were likely exposed to additional stimuli giving rise to the biphasic phenotype.

p53 immunohistochemistry revealed the epithelial and sarcomatoid areas of all 17 cases to have similar staining characteristics in both pattern and quantity. This further supports the biological and molecular similarities between these two morphologically distinct components. The fact that only $40 \%$ of the cases harboring TP53 mutations had positive nuclear p53 staining suggests that TP53 mutations may be only one of the factors resulting in an altered p53 signal system. ${ }^{25,29,30}$

In summary, our discovery of identical TP53 mutation patterns and nuclear p53 immunohistochemical staining characteristics in both the epithelial and sarcomatoid components suggests a common clonal origin of the phenotypically distinct tumor components of sarcomatoid carcinoma of the urinary bladder.

\section{References}

1 Eble JN, Sauter G, Epstein JI, et al. World Health Organization Classification of Tumours: Pathology and 
Genetics of Tumours of the Urinary System and Male Genital Organs. IARC Press: Lyon, 2004.

2 Inagaki T, Nagata M, Kaneko M, et al. Carcinosarcoma with rhabdoid features of the urinary bladder in a 2-year-old girl: possible histogenesis of stem cell origin. Pathol Int 2000;50:973-978.

3 Lott S, Lopez-Beltran A, Montironi R, et al. Soft tissue tumors of the urinary bladder. Part II: Malignant neoplasms. Hum Pathol 2007;38:807-823.

4 Lopez-Beltran A, Pacelli A, Rothenberg HJ, et al. Carcinosarcoma and sarcomatoid carcinoma of the bladder: clinicopathological study of 41 cases. J Urol 1998;159:1497-1503.

5 Kanno J, Sakamoto A, Washizuka M, et al. Malignant mixed mesodermal tumor of bladder occurring after radiotherapy for cervical cancer: report of a case. J Urol 1985;133:854-856.

6 Dent Jr ED. Carcinosarcoma (collision tumor) of the urinary bladder. J Urol 1955;74:104-108.

7 Hejtmancik JH, Klatt WW. Co-existing carcinoma and sarcoma of the bladder. J Urol 1960;84:320-321.

8 Holtz F, Fox JE, Abell MR. Carcinosarcoma of the urinary bladder. Cancer 1972;29:294-304.

9 Mackles A, Immergut S, Grayzel DM, et al. Carcinoma and sarcoma of bladder: report of unusual simultaneous occurrence of both tumors. J Urol 1948;59: 1121-1126.

10 Melicow MM, Uson AC. Multiple unrelated primary malignancies of the genitourinary tract. J Urol 1957;77: 96-105.

11 Carter RD, Powers JH, Van Hawn CZ. Osteogenic sarcoma and transitional cell carcinoma occurring simultaneously in the urinary bladder: report of a case. J Urol 1956;76:263-269.

12 Lahoti C, Schinella R, Rangwala AF, et al. Carcinosarcoma of urinary bladder: report of 5 cases with immunohistologic study. Urology 1994;43:389-393.

13 Wick MR, Swanson PE. Carcinosarcomas: current perspectives and an historical review of nosological concepts. Semin Diagn Pathol 1993;10:118-127.

14 Greene FL, Page DL, Flemming ID, et al. American Joint Committee on Cancer Staging Manual. SpringerVerlag: New York, 2002.

15 Cheng L, Gu J, Ulbright TM, et al. Precise microdissection of human bladder carcinomas reveals divergent tumor subclones in the same tumor. Cancer 2002;94: 104-110.

16 Cheng L, Zhang S, Wang M, et al. Molecular genetic evidence supporting the neoplastic nature of stromal cells in 'fibrosis' after chemotherapy for testicular germ cell tumors. J Pathol 2007;213:65-71.

17 Cheng L, Jones TD, McCarthy RP, et al. Molecular genetic evidence for a common clonal origin of urinary bladder small cell carcinoma and coexisting urothelial carcinoma. Am J Pathol 2005;166:1533-1539.

18 van der Sijp JR, van Meerbeeck JP, Maat AP, et al. Determination of the molecular relationship between multiple tumors within one patient is of clinical importance. J Clin Oncol 2002;20:1105-1114.

19 Uchida $\mathrm{T}$, Wada $\mathrm{C}$, Ishida $\mathrm{H}$, et al. p53 mutations and prognosis in bladder tumors. J Urol 1995;153: 1097-1104.

20 Cheng L, Sebo TJ, Cheville JC, et al. P53 protein overexpression is associated with increased cell proliferation in patients with locally recurrent prostate carcinoma after radiation therapy. Cancer 1999;85: 1293-1299.

21 Cheng L, Leibovich BC, Bergstralh EJ, et al. p53 alteration in regional lymph node metastases from prostate carcinoma: a marker for progression? Cancer 1999;85:2455-2459.

22 Perret L, Chaubert P, Hessler D, et al. Primary heterologous carcinosarcoma (metaplastic carcinoma) of the urinary bladder: a clinicopathologic, immunohistochemical, and ultrastructural analysis of eight cases and a review of the literature. Cancer 1998;82: 1535-1549.

23 Sung MT, Wang M, Maclennan G, et al. Histogenesis of sarcomatoid urothelial carcinoma of the urinary bladder: evidence for a common clonal origin with divergent differentiation. J Pathol 2007; 211:420-430.

24 Gronau S, Menz CK, Melzner I, et al. Immunohistomorphologic and molecular cytogenetic analysis of a carcinosarcoma of the urinary bladder. Virchows Arch 2002;440:436-440.

$25 \mathrm{Wu}$ XR. Urothelial tumorigenesis: a tale of divergent pathways. Nat Rev Cancer 2005;5:713-725.

26 Malats N, Bustos A, Nascimento CM, et al. P53 as a prognostic marker for bladder cancer: a meta-analysis and review. Lancet Oncol 2005;6:678-686.

27 Cheng L, Zhang D. Molecular Genetic Pathology. Humana Press/Springer: Totowa, NJ, 2008.

28 George B, Datar RH, Wu L, et al. p53 gene and protein status: the role of p53 alterations in predicting outcome in patients with bladder cancer. J Clin Oncol 2007;25:5352-5358.

29 Salinas-Sanchez AS, Atienzar-Tobarra M, LorenzoRomero JG, et al. Sensitivity and specificity of p53 protein detection by immunohistochemistry in patients with urothelial bladder carcinoma. Urol Int 2007;79:321-327.

30 Oyasu R, Nan L, Szumel RC, et al. p53 gene mutations in human urothelial carcinomas: analysis by immunohistochemistry and single-strand conformation polymorphism. Mod Pathol 1995;8:170-176. 